\title{
Causes of Fiber Cut and the Recommendation to Solve the Problem
}

\author{
Teddy Hayford-Acquah ${ }^{1}$, Ben Asante ${ }^{2}$ \\ ${ }^{I}$ (The Department of Engineering and Management/The Graduate School/Ghana Technology University \\ College, Ghana \\ ${ }^{2}$ (The Department of Electrical and Telecommunication Engineering, The College of Engineering/ Ghana \\ Technology University College, Ghana)
}

\begin{abstract}
Optical fiber technology has transformed the telecom landscape in Ghana in recent years owing to its overwhelming advantages over the traditional transmission medium. Though the technology is highly immune to electromagnetic wave, it also offers a higher capacity of bandwidth for data and voice activities. The fiber infrastructure in Ghana has experienced a lot of fiber cuts incidences. And this has affected network quality delivery, increased operational expenditure and decline revenue margins of the telcos. This research was carried out in two phases using MTN Ghana (Western and Central Region) as a case study, to establish the root causes and remedial actions to curb it. First, Pareto and Ishakawa analytical tools were applied to the primary source data for the analysis. Secondly, a purposive survey was administered to acquire additional information. It was established that activities of government sponsored projects and private developers were largely responsible for the menace due to; negligence, ignorance, lack of coordination etc. On the bases, it's recommended that telcos and stakeholders embark on educational campaign to sensitize the public on optical fiber cables whiles the government of Ghana put in measures to build mandatory right-of-way with support from the private sector.
\end{abstract}

Keywords: Fiber Optic, Ishakawa, Pareto, Private Sector, Right-of-way

\section{Introduction}

Good customer experience, high bandwidth capacity, high network reliability and resiliency, and high quality of service delivery are some of the demands on telecommunications network operators in Ghana to drive various voice and data service on the respective mobile cellular network technologies such as Second Generation (2G)/Global System for Mobile Communication (GSM), Third Generation (3G)/Universal Mobile Telecommunication Service (UMTS) and Fourth Generation (4G)/Long Term Evolution (LTE). Fiber optics network technology is generally accepted in the telecom industry as the most fastest and widely used medium of backhaul transmission that offers the required capacity and capability to meet the required telecom needs of customers in the industry today (Dhliwayo, 2012).

The technology provides an enhanced features and advantages that is superior over copper-based and wireless backhaul transmission solutions. In view of this, most network operators in the industry in Ghana have deployed hundreds of kilometers of optical fiber network infrastructures across the length and breadth of the county in their bid to deliver a high standard network quality that satisfies and delight the needs of their customers.

However, besides the superior and attractive features of the optical fiber technology upon which the telecom operators have leverage on to extend network coverage to many part of the country, its deployment and effective maintenance to ensure that the full benefits of the technology is maximized has been characterized with persistent fiber cut by various activities, posing many challenges to the players of the industry in meeting the network quality expectation of both regulators and the customers (Banigbe, 2014).

This paper therefore seeks to investigate the root causes of persistent fiber cuts in the telecom industry in Ghana (Case study in MTN Ghana, Western and Central Region), with a stronger conviction that the outcome of the investigation when implemented will improve on general network quality of service delivery of the various network operators in Ghana which are attributed to frequent fiber cuts, reduce their cost of operations and also improve on customer satisfaction.

\section{Problem Statement}

Over the past decade it has become apparent that fiber optics technology is steadily replacing the conventional microwave transmission system in the telecom landscape due to its superior and attractive features over the conventional transmission medium (Held, 1999).

In Ghana, almost all the telecom network operators have opted for the fiber optics technology as their primary transmission medium on their backhaul network design infrastructure. 
In spite of its superior and attractive features which fiber optics technology have over the conventional transmission technique, the industry has been faced with a number of challenges both in the deployment as well as maintenance of the infrastructure. Persistent fiber cut has been the most significant challenging issue to deal with by the telecom companies in the industry in Ghana today. The fiber cut is having a tremendous negative effect on quality of services delivery and customers experience (Domfeh, 2012).

Besides these, other mandatory key performance indicators (KPI) relative to industrial standards set by the regulator; such as availability, reliability, call set-up success rate (CSSR), call congestion rate, drops call rate (DCR) as well as subscriber connectivity for both voice and data are significantly impacted due to frequent fiber cut phenomenon.

This paper therefore seeks to investigate and ascertain the root cause(s) of frequent fiber cut and suggest recommendation for optimization to curb the situation.

\section{Objective}

The main aim of this paper study is to,

- investigate and establish the root causes of the fiber cut in the telecommunication (telecom) industry in Ghana

- recommend possible mitigation measures to curb the menace.

\section{Methodology}

- Studied the relevant literature material available on the topic.

- Consulted respective telecom operators in Ghana for information on fiber optics network design.

- Obtained data on fiber cut from telecom companies (ie MTN Ghana)

- Issued questionnaire to solicit information on the topic from telecom companies.

- Applied the Pareto and Ishakawa models to ascertain the most significant cause of the fiber cut.

\section{Scope of Work}

This work is limited to investigating, establishing the root causes and the main factors accounting for frequent fiber cut menace and making recommendation to curb the occurrence of the phenomenon.

\section{Justification}

The recommendations of this paper when implemented will improve network quality of service delivery in the telecom industry in Ghana in terms of high network availability, reduction in call drop rate, increase in call set-up success rate, decrease in congestion on both voice and data services which in effect improve customer satisfaction

\section{Introduction}

\section{Literature Review}

Ezeh et al (2013) defines optical fiber communication as a method and a mode of transmitting information from one place to another by sending pulses of light through an optical fiber. It's principle of operation is based on the refraction of light, thus, it transmits data at the speed of light. Generally, Fiber optics cable is a medium for carrying information from one point to another in the form of light. Unlike the copper form of transmission, fiber optics is not electrical in nature. A basic fiber optic system consists of a transmitting device that converts an electrical signal into a light signal, an optical fiber cable than carries the light, and a receiver that accepts the light signal and converts it back into an electrical signal (Massa, 2000).

According to Marcus (2012), data or voice signals is transmitted on the optical cable in the form of light will continues to travel in a straight line in a homogeneous media until it hits or encounters an object or an obstruction where it will either be absorbed, reflected or refracted.

And according to Crawford (1993), Fiber optics cable, whose size often less than one inch in diameter, routinely carry tens of thousands of telephone calls over glass strands slightly more thicker than a human hair. He further emphasized that the optical fiber technology has become an integral part of the operational system of many other sectors of our economy, such that when the infrastructure is damaged or its fails as a result of cut on the physical layer vital communication links to airline industry (e.g. airport), health service (e.g. emergency services), power industry (e.g. nuclear power facility), banking industry (e.g. mobile financial services) etc. are interrupted.

Therefore, optical fiber network infrastructure in the information and communication industry could refer to the optical cable and complementary network element which are deployed or installed to connect two or more nodes and/or hub sites, over which voice and/or data traffic or signals in the form of light is transmitted from one point to the other. The interconnection of these sites with the optical cable within a given area(s), 
town(s), across cities, region(s), countries and continent(s) in the form of ring, star or bus topology, aggregate to form the optical fiber network infrastructure.

\section{OPTICAL FIBER NETWORK INFRASTRUCTURE IMPLEMENTATION METHODS}

According to Massa (2000), in general, fiber optic cable can be deployed or implemented using three method or technique relative to the environmental condition.

\section{1) Arial or Overhead Installation}

This form of installation required that optical fiber cables is strung from telephone lines. According to Johnson (2009) these installation methods of optical aerial cable include the normal practices for both self-supporting cables (all dielectric or including a metallic element) and lashed cables (e.g. attached to a pre-installed tension strand).

\section{2) Underground Optical Cable Installation}

This form of installation required that the optical fiber cables are buried in the earth with or without duct according to the right specification. The two most common ways in which underground optical cable can be deployed are either direct burial or indirect burial.

\section{Direct Burial Installation}

This method of deployment are the most common for long cross-country optical network infrastructure. The cables plowed in or buried in trench directly. The optical fiber cable type often used are steel armored. The advantages of the direct buried is that it can be deployed very quickly. It is also required that best installation practices such as burying the cable at the right depth (ie should be less than $1.5 \mathrm{~m}$ ), placing warning taps or labels buried directly above the cable, proper backfilling must be done, deployment of market poles and observing of minimum bending radius and maximum rated cable load must be applied in accordance with installation best practice (Anon, 2013).

\section{Indirect Burial Installation}

In this type of deployment, ducts are used to protect the cable from harsh environmental condition, cables are placed in a conduits or sub-duct and buried below the earth surface, then a warning taps or labels are buried directly above the cable before final backfilling is done. It is required that the dag trench must be straight as possible. It is also required that best installation practices such as burring the cable at the right depth (ie should be less than $1.5 \mathrm{~m}$ ), proper backfilling must be done, deployment of market poles and observing of minimum bending radius and maximum rated cable load must be applied.

The advantages of this method of installation are;

i. Easy future expansion. No need to dig again as spare duct can be deployed for future expansion.

ii. Installation are easy when non-armored optical fiber are used

iii. It is suitable for urban areas

iv. It is less expensive.

However, a trenchless technology is applied in areas and environment where the traditional digging techniques is not suitable. For example when the optical cable needs to be deployed across a river and railway. For these situations a directional drilling machines can be used. Drilling is started directly from the surface using a fluid assisted directional drilling system (Johnson, 2009).

\section{3) Submarine Installation}

In this method of installation the optical fiber cable are deployed underwater in deep sea, including transoceanic applications. It's the only long cross-continental method of deploying optical network infrastructure. Johnson (2009) cited in an international communication union manual that, optical fiber submarine cable systems are an important element of telecommunication networks because they allow the connection of terminal stations divided by a sea. These links can be of various lengths, starting from a few kilometers (for linking to islands just offshore) up to several thousands of kilometers (for linking different continents through the oceans).

\section{Pre-Implementation Requirement 4) Right-Of-Way (ROW)}

Irrespective of the that facts that optical fiber technology is globally accepted as the way forward to address the high demand for transmission backhaul bandwidth capacity in the information and communication industry, could mean that any organization or telecom company could just "go to market" and commence implementation or installation of fiber optics infrastructure anywhere anyhow. The deployment of the infrastructure is regulated and requires that any organization or communication company with the intent to 
deploy optical fiber infrastructure should secure permit from the right agencies and regulating bodies. The permit granted to deploy the optical fiber infrastructure in a specific given location(s) is what is referred to as Right-of-Way (ROW). Traditionally, a right of way provides the right to pass across the lands of another, usually in a strip, acquired for or devoted to building facilities such as roads, railroads, or utilities. Generally, ROW can be publicly or privately owned (Anon, 2008).

In Ghana, ROW is often and formally issued by the public agency (state agencies), and such state agencies includes;

i. Ghana Highway Authority. ii Department of Urban Roads. iii Metropolitan/Municipal/Districts Assemblies

iv. Environmental Protection Agency

The permit obtained at a fee is a confirmation that, the proposed route per organizations engineering drawings to deploy the infrastructure is approved. Normally, the conditions for obtaining ROW for the various method or techniques differs. This paper shall discuss only ROW related to overhead and underground optical cable deployment.

In Ghana, Gyaase and Takyi, (2014) has suggested that government investment in these passive infrastructure make them more efficient because governments have access to majority of the rights-of-way, and lease them to the communication companies. Williams (2010) also share the same thought that investing into restructuring and redesigning and making the rights -of-way readily available to network developers at low cost should be the way forward in addressing most of the issues accountable for the frequent fiber cut.

\section{FIBER CUT}

Definition

Grover (2004) and Hoffman (2002) defines an outage and an optical cable cut respectively as an event that arises from a failure that has actually occurred. And an incidents where a communication cable is damaged, effectively disrupting normal operations and typically requiring an emergency repair response. Hence, the phenomenon of fiber cut in the telecom industry can be described as an act of interrupting an active optical cable connected to network element resulting from specific activities which is/are carried out close to the location(s) where these optical cables are deployed.

The occurrence of this phenomenon often disrupt or causes network outages and the level of the impact of the network outage is dependent on the numbers of cut(s) and the location(s) of the cut in a given time.

Additionally, the effect of this menace in the telecom industry has significant effect on the network quality delivery (on both voice and data traffic) as well as the cost of operation and revenue margin.

\section{Fiber Cut Phenomenon}

Over the years many studies have been conducted into the occurrence of the fiber cut incident to establish the root causes accounting for the frequency of the cut, its impact on the network quality of service delivery and many others. Shake et al (1999) critically reviewed another dimension of the root cause of fiber cut in the optical fiber network infrastructure. The paper analyzed the phenomenon by assessing the vulnerability of the optical fiber network infrastructure to physical layer attack. Where physical layer according to the paper refers to the optical fiber cable layered either overhead or underground. In his argument, though he mentioned other factors that account for the fiber cut on the infrastructure that has been dig-up activities as well as constructional activities, his analysis was focused on attacks that attempts to deny or disrupt active service via the fiber cable. He expressed that it is an act of willful intent to destroy or cause damage to the optical infrastructure for the purpose of getting a reward be it an intrinsic or extrinsic.

Upon that bases a model was developed to address the vulnerability and survivability issues associated to fiber cut accounted for by attackers on the optical fiber network infrastructure. The model was propounded using a mathematically evaluated tool that can assess the degree of the impact on the various network topology to such attack.

Though the principle worked theoretically by simulation, using a MATLAB programmable algorithm to assess the physical and the topological vulnerability in high rated and wide area network. It's however unclear whether or not the same results (i.e., reducing the degree of network disruption, duration of outage and ease of attack) will be achieved when the concept or the model is applied to a real live network. Moreover, his discussion and analysis was limited in terms of historical data to demonstrate and justify why the trend is worrying in respect of frequency at which such incidences are occurring as well as the duration for the respective outages.

Ezeh et al (2013), conducted a related research in South-Eastern Nigeria to establish the severity index of the problem associated with the deployment of optical fiber network infrastructure. The objective of his research was to identify and statistically evaluate and appraise the main factors accounting for the root causes of 
fiber cut menaces on the optical communication infrastructure in Nigeria. His research analysis and evaluation led to the identification of 17 problems accounting for the root causes of the fiber cut.

In the root cause analysis, he further grouped the problem into four main category, namely; Governmental, Man-Made, Planning and Design related issue and Natural problems. The outcome of the research formulated on the bases of the data collected from questionnaire administered by 26 telecom operators and 23 Nigeria Communication Commission personnel. The information was then analyzed statistically to establish the severity index and the degree of ranking for each category of the problem identified.

Though his findings and conclusion were consistent and coincided they were more of reactive recommendation than proactive. However, this paper is of the view that all various institutions and organizations who are actors and key players in the acquisition and regulation of the ROW need to be well resourced and empowered in order to drive a common framework aimed at eliminating or reducing the occurrence of the incidence. This is important because once the infrastructure is deployed and made to carry traffic, any network outages or failure as a result of the fiber cut compromises national security. Finally, Crawford (1993) also conducted a similar research to ascertain the causes of optical fiber cable dig - up in the telecom industry and further recommended measures to cure or reduce the menace.

Crawford's investigation was centered on establishing the factors that responsible for frequent fiber optics cable failure caused by dig - up. In his approach, he set up a focused group to collect data on optical fiber cable failure for analysis from selected telecom companies, surveyed existing utility damage prevention legislation and held discussion with key representatives from damage prevention industry.

During the investigation he established that between 1990 and 1992, optical fiber cable failures was the single largest causes of network outages which affected over 50,000 customer for over 30 minute per each incident. Further analysis lead to the classification of the data analyzed to immediate causes and root causes.

The immediate causes are the direct causes accounting for the cable cut (e.g., dig-up). The general outcome of the entire investigation established weak laws as one of the primary reasons for the continuing cutting or damaging of the optical fiber cable. He said, this is because $40 \%$ of the total cable failure recorded happened in locations or areas with accurate cable location, proper temporal markers of sub-surface cable route (in order words proper prior notification were made to the excavator). On the other hand, 33\% of the $60 \%$ attributed to fiber dig-up in the industry was the result of excavation activities by the government and private property owners.

In the final analysis, Crawford applied Pareto analysis tool to identify the most significant cause of the failure and on the bases of his finding made a significant and relevant recommendation that when implemented could go a long way to curb the optical fiber cut menace if not eliminated. However, he could have complemented the Pareto tool with Ishakawa tool which is an analytical tool used for identifying the causes and effect of a problem to make his conclusion more focused on the actual root causes of the contributing to the fiber cut menace in the jurisdiction under discussion.

\section{B. RESEARCH APPROACH AND DESIGN}

\section{Research Methodology}

C. The combination of qualitative and quantitative method or approach was adopted to this research because, the research aimed at identifying main factors and their corresponding root causes accounting for the frequent fiber cuts on the optical fiber network infrastructure and its associated impact in the telecom industry in Western and Central Regions of Ghana.

\section{Study Organization}

This research was carried out in the South-West Business Districts of MTN Ghana. MTN Ghana is one of the 22 operating countries (OpCo) under MTN Group in Africa, Asia and the Middle East connecting to over 232.5 million subscribers across it footprint. The organization is a leading provider of telecommunications services in the telecom landscape in emerging markets such as Afghanistan, Benin, Botswana, Cameroon, Cote d'Ivoire, Cyprus, Ghana, Guinea Bissau, Guinea Republic, Iran, Liberia, Nigeria, Republic of Congo (Congo Brazzaville), Rwanda, South Africa, Sudan, South Sudan, Swaziland, Syria, Uganda, Yemen and Zambia, with the mission of providing a world-class telecommunications products and services, through innovative and sustainable corporate social investment initiatives. The company was founded in 1994 and is based in Johannesburg in South Africa.

Ghana became part of the MTN Group following the acquisition of Scancom Limited in 2006 which operated under the trade name Spacefon. MTN has the widest, most robust $2 \mathrm{G}, 3 \mathrm{G}$ and $4 \mathrm{G}$ coverage across the length and breadth of Ghana with over $50 \%$ market share of the telecom industry in Ghana. Presently, MTN Ghana has deployed over 5,000 km of nationwide optical fiber network infrastructure connecting to over 2,500 operational cell sites and three state-of-the-art switch and data center. Besides the traditional voice and data services which the organization provides, it also provides tailor made product and service such as mobile 
financial services, ICT solution for SME, asserts tracking devices etc., which are designed to address the specific telecom needs and lifestyle of it subscribers.

Its operations in Ghana is sub-divided into three Strategic Business Unit (SBU); Northern Business Unit which is a composite of the Northern Region, Upper-Easts Region, Upper-West Region, Brong Ahafo Region and Ashante Region; part of Eastern Region, Volter Region, and Greater Accra Region also constitute the South-East Business Unit; whiles South-West Business Unit is made up of part of Eastern Region, Central Region and Western Region.

The various function of the organization under the respective SBU's are further divided into division, department and section which drives the overall strategic objectives and goals of the entire MTN Ghana organization.

The divisions and departments that drives the comprehensive operational activities of the organization includes; The Marketing, Sales \& Distribution, Mobile Financial Service and Enterprise Business Division. These divisions are technically responsible for creating the route to the market as well as communicating to the customers and corporate institution about MTN's tailor made product and services such as Network Solutions, Internet \& Messaging Solutions, Data Center Services, Calling Solutions, Security Solutions Cloud Services etc., besides the traditional voice and data services on offer, through advertising, pricing and promotions. The Human Resource Division/Department, plays a critical role in the function of the entire organization. It's responsible for supporting and creating an enabling environment for learning and developing for employees who are already on the job as well as talented individuals who have join MTN.

Another important division in the organization is the Capital Group Division and Network Group. These two divisions are basically responsible for the building and maintaining the fix and physical assets (eg. cell sites, switches and data centers, branch offices etc) of MTN respectively. Whiles the maintaining and enhancement of the integrity and controls over the company's financial assets and liabilities as well as the financial statements of the organization is the full responsibility of the Finance and Services Division.

Lastly, the Customer Care Division is basically responsible for attending to the needs of MTN customers at the respective branch network offices across the country. Whiles the Information Services Division focuses on creating an enabling business environment to grow profitably by providing cost-effective technological platforms that effectively manages information flow both internally and externally and also supports the various solution the organization provide.

Finally, the Corporate Service Division. Their responsibility is to ensure that good corporate governances which includes communication, regulatory and foundation activities are adhered to.

\section{The Study Population and Sample}

According to Burns and Grove (1993) all elements (individuals, objects and events) that meet the sample criteria for inclusion in a particular study is referred to as population. Lavrakas (2008) also defines a population as any limited or unlimited gathering of distinct elements in which we are interested to undertake a study. In this research study, two set of population were utilized for the consolidation of data for the discussion and analysis. The first targeted population was MTN, the organization under study and the owners of the optical fiber network infrastructure. The second targeted population was the thirty party vendor, they providing managed service for MTN on their optical fiber network infrastructure. Their core responsibility is to conduct preventive and corrective maintenance activities on MTNs optical fiber network infrastructure, and also make recommendation to MTN with respect to areas on the network that requires optimization to enhance the resiliency of the fiber optics network infrastructure, where applicable.

The sample space for the analysis of this study shall be a derivative of MTN and its vendor in the South-West Business Unit (ie Western \& Central Region), the jurisdiction under study.

The method or technique applied for the selection of the sample space was a direct and purposive, targeted at specific key staff(s) of these organizations who has the technical "know-how" or has the requisite expertise to provide the required information on the problem statement under study. According to Babbie (2007) purposive sampling is the selection of a sample space on the basis of once knowledge of the population, its elements, and the nature of your research aims.

\section{Data Collection/Sources of Data}

According to Burns \& Grove (1993), the information obtained through a questionnaire is similar to that obtained by an interview, however, the information obtained through direct interviews provides more detailed insight than that which was obtained through questionnaire.

In this research study both techniques for collecting data were adopted in order to fully establish a clear case for the defined problem.

A secondary data which was obtained through administering of questionnaires for analysis and discussion in line with the objectives of this study. Prior to secondary data analysis, a data on major network outages recorded 
within the period of this study, which the fault reasons for the respective outages were established to be as a result of fiber cuts was thoroughly evaluated and analyzed in line the objective study using Microsoft excel. And this major network outages data became the primary sources of data for this research study.

\section{1) Primary Data Sources}

As earlier mentioned, the primary source of data for this research was an obtained data from the organization on major network failure attributed to fiber cut on the optical network infrastructure for the jurisdiction under study, between the periods of January 2014 to August 2016. Below are some of the relevant information on the data to aid in the discussion and analysis;

i. The duration for each outage accounted for by fiber cut.

ii. The various network technologies that are impacted during each outage (ie only $2 \mathrm{G}$ or only $3 \mathrm{G}$, only $4 \mathrm{G}$, or only $2 \mathrm{G} \& 3 \mathrm{G}$ or all).

iii. Whether or not a particular network outage resulting from fiber cut was traffic affecting or non-traffic affecting.

iv. The network type (backbone or metro/FTTx) on which a particular fiber cut incidence occurs.

v. The activity(s) that accounts for a particular fiber cut.

vi. Whether or not the various cell sites are classified or categorized. And if yes what are the categories and what is the impact of the each cut on the respective categories.

\section{2) Secondary Data Sources}

Secondly, in order to obtain some specific information which was not available in the primary data, a purposive sampling in the form of a questionnaire was administered on the Regional Senior for Network Field Operation of MTN for Southern Ghana, Fiber Implementation Manager for MTN Ghana and the Regional Manager of the Manage Service Provider (WR\&CR) to sources further information in the following areas;

i. The fiber population in MTN Ghana (ie WR\&CR).

ii. The network type deployed in that jurisdiction; whether or not they were inter-cite/backbone or metro fiber route.

iii. The type of network topology deployed whether or not fiber network deployed in regions were operational on the ring topology, star topology, mesh topology or linear topology.

iv. The frequency at which the fiber cut incidence were occurring (ie., once, twice, thrice or more)

v. The nature of the fiber cut, whether or not they are single cut, double cut or triple cut. And whether or not they are occurring at the same time or different time or at a specific time interval.

vi. Establish the gravity of the impact when it's a single fiber cut, double fiber cut and/or triple fiber cut.

vii. The causes of the fiber cut along the various corridor of the regions. Whether or not the occurrence were deliberate or accidental.

\section{Data Analysis Methodology}

The consolidated data obtained from the sample space studied for the purpose of this research was subjected to various analytical and statistical methods to arrive at the results or findings and conclusion. And on that bases recommendation were made. The Pareto and Ishakawa analytical tools were identified as the most relevant models in addition to Microsoft Excel, when applied to the data generated the required results in terms comparing the variation in the failure rate, the failure severity and establishing of the root causes and the main factors accounting for the respective fiber failures.

In a citation by Doshi et al (2012) it was argued out that to identify the root causes of a problem and to come to the accurate conclusion, systematic approach such as Ishikawa diagram technique has to be implemented. Ishikawa diagram basically is an analysis tool that provides a systematic way of looking at effects and their respective causes.

According to Patel et al (2014) a Pareto Chart is simply a frequency distribution (or Histogram) of attribute data. It consists of a series of bars whose heights reflect the frequency or impact of problems. The bars are arranged in descending order of height from left to right. Bhosale et al (2013) also described the analytical tool as the $80 / 20$ rule applied to quality-control. The principle simple states that about 80 percent of the problems come from 20 percent of the causes. Hence the model was used to a classify main causes or groups or categories of various fault reasons of the fiber cuts on the optical netwok infrastructure to identify the top $20 \%$ of causes that needs to be addressed to resolve the $80 \%$ of the fiber cut problems in the network.

\section{Limitation}

Generally, this study has been comprehensively put together based on the available information in the subject area been researched. However, there were some encountered limitation during the study; 
Firstly, there were no enough books, articles and journals in the subject area. Furthermore, the researchers could not have access to database from other communication providers in Ghana.

Secondly, the study could not secure absolute figures from the organization under study in respect to the revenue generated per site to enable quantifying the actual revenue loss to the organization as a result of the impact of the menace. Hence, available figures already in the public domain in addition estimated figures provides in the questionnaire were extrapolated and utilized for the analysis to arrive at a reasonable estimated cost.

Thirdly, the major network failures data accounted for by fiber cut which was reviewed did not provide information on the various category of sites involved per each outages.

Also, the data did not provide adequate information on the respective outages whether or not the cut experiences were as a result of single, double or triple cut.

\section{Introduction}

\section{Analysis And Discussion}

According to the Senior Manager for MTN Ghana, for Network Field Operations, responsible for Southern Ghana, MTN Ghana has deployed in excess of about One Thousand Two Hundred and Four kilometers $(1,204 \mathrm{~km})$ of optical fiber network infrastructure in the Western and Central Region (WR\&CR) spanning from Kasoa through Cape Coast to Takoradi and from Takoradi through Apimanim to Elubo. The layout provides further details showing the backbone footprint of the optical fiber backbone network infrastructure in WR\&CR generally.

In a policy document citation titled Utility Corridor Management under land management policies of the ministry of natural resources of Ontario in Canada, dated October 2006, defines utility corridor or road reservation as a linear strips of land that run through public land to secure access between two points for the purpose of transmitting and distributing hydrocarbons, electrical energy or telecommunication services and includes such facilities as poles, towers, wire, cable (including fibre optic cable), apparatus or other thing that is used or is capable of being used for any operation directly connected with providing the service. Similarly in Ghana, the right-of-ways procured for optical fiber cables deployment are developed within this existing corridor or reservation.

MTN's network infrastructure in the Western and Central Region is a composite of intercity/backbone and metro/fiber-to-transmission (FTTx) to ensure network efficiency and resiliency. The intercity fiber network forms the main backbone infrastructure which connects one region to the other in a ring network topology along its footprints. Likewise, the metro/FTTx, but in this case they are deployed only within the city centers or the metropolises to reinforce the network robustness in the strategic business district (SBU). In pursuance of this, seven (7) metro/FTTx rings has been fully deployed and operationalize guarantee that level of network robustness and resiliency to support the various services that depends on it.

Hence the fiber cut menace or phenomenon been investigated in this study is not limited to either of two network types mentioned is this discussion, but rather both the intercity/backbone and the metro/FTTx network been subjected to this phenomenon. And this was very evident in the primary data procured for the analysis in this study.

It was also further identified that the happening of fiber cut incidences were resulting into network outages which were affecting services which were not limited to only the traditional voice and data service but also the certain services such mobile money, tracking solutions, etc., which also rely on the optical fiber network stability for its efficient operation. All incidences which occurs due to fiber cut and resulted in network outages were referred to as traffic affecting (TA) fiber cuts whiles incidences which did not result in any network outages were referred to as non-traffic affecting (NTA) fiber cuts.

The Senior Manager for Network Operation further indicated that traffic affecting fiber cuts incidences on both backbone and metro fiber infrastructure happens due to double or triple fiber cuts. Generally, double or triple fiber cut is a situation whereby the fiber network infrastructure suffers more than one fiber cut incident, either simultaneously or at separate, but very short time interval at different locations on the infrastructure within a particular jurisdiction.

Therefore, in line with objectives of this study, the analysis and discussion of this research in this section was classified into two parts in order to first establish the root causes and their main factors accounting for them. And secondly, assess the impact of the root causes.

Part one analyzed the primary source data for this study manually using Microsoft Excel and established the various categories or classification, accounting for the fiber cut incidences on the fiber network infrastructure and further applied Pareto analytical tool to evaluate the top $20 \%$ category(s) that ought to be further analyzed to establish their respective root causes as well as main factors responsible for the phenomenon and further recommend mitigation action to address $80 \%$ of main factors of the root causes accounting for the fiber cut phenomenon. 
Subsequently, Ishikawa diagram, also known as Causes-and-Effects diagram was applied to the results of the above analysis to identify actual factors accounting for the said root causes of the various categories identified. In part two, the analysis focused on evaluating the impact of the fiber cut on the operation of the organization based on the primary sources data. Then further evaluation was sought to analyze and to establish the quantitative impact of the incidences in relation to organizations operational expenditure as well as revenue loss attributed to fiber cut menace within the period and the jurisdiction under study. And possibly assess the translational effect of the incidences on quality of service delivery to the customers of MTN (ie customer experience).

\section{3) Primary Data Analysis and Evaluation}

From the primary data analysis and evaluation, it was established that 908 counts of fiber cut incidences had been recorded on the optical fiber network infrastructure in WR\&CR between the period of January 2014 and August 2016. Out of the total cut incidences which occurred, 848 counts were recorded with faults reasons whiles 59 counts were recorded without fault reasons representing $93.50 \%$ and $6.50 \%$ respectively. The reasons for the counts of failures which were recorded without any reasons assigned them could not be immediately established. Therefore, in order for the researcher of this paper to statistically tally and accurately categorize the main fault reasons and further establish the root causes, the analysis was focused in the 93.50\% fault counts with respective fault reasons as shown in Table 4.1 below.

\begin{tabular}{|l|c|c|c|c|}
\hline \multicolumn{2}{|c|}{$2014-2016$ Fiber Cut With Fault Reason_BB vs MFTTx } \\
\hline $\begin{array}{c}\text { Type Of } \\
\text { Network }\end{array}$ & $\begin{array}{c}\text { Count of } \\
\text { Failure }\end{array}$ & $\%$ & $\begin{array}{c}\text { Traffic } \\
\text { Affecting } \\
(\%)\end{array}$ & $\begin{array}{c}\text { Non-Traffic } \\
\text { Affecting } \\
(\%)\end{array}$ \\
\hline Backbone & 478 & 56.30 & 12.13 & 87.87 \\
\hline Metro/FTTx & 371 & 43.70 & 45.82 & 54.18 \\
\hline Total & 849 & 100.00 & & \\
\hline
\end{tabular}

Table 4.1 (a) 2014 - 2016 Summary of Fiber Cut with Reasons

From above data reviewed, it was observed that, there were 478 counts of recorded fiber cut incidences with fault reasons happening on the backbone network, representing $56.30 \%$ of the total fault incidence within the two years, eight months period. Out of this, $12.13 \%$ were traffic affecting fiber cut incidences whiles $87.87 \%$ were non-traffic affecting fiber cut incidences. During the same period the metro fiber/FTTx network also experienced 371 count of fiber cut incidences, representing $43.70 \%$ of the total fiber failures within the years under review. The percentage contribution of traffic affecting and non-traffic affecting incidences on the metro fiber/FTTx network was $45.82 \%$ and $54.18 \%$ respectively.

According to the Senior Manager for Network Field Operation for Southern Ghana, the correlation between the fault counts and the impact level is an indication of a highly resilient network, in the sense that the level of network resiliency and robustness is directly dependent on the number of redundancies implemented to support the active services on the network or depends on the fiber infrastructure, in the event of network challenges such as fiber cut. This explains why statistically from Table 4.1(a) there are high count of fiber cut on both the main backbone and metro/FTTx network, but the ratio of the non-traffic affect fiber cut to traffic affecting fiber cuts is low or minimal.

In a responds to the questionnaire administered, it was established that network outage resulting from fiber cut have always affected service when the cut incidences is more than one (ie either double or triple fiber cut), with incidence occurrence time been the same or at a short interval at different location within the WR\&CR network infrastructure. Though cumulatively 849 counts of network outage resulting from fiber cut incidents were recorded with various degree of impact, not all the cut incident recorded were of the same root causes neither the factors accounting for the root causes were the same as well.

Based on the primary source data analyzed parallel with the questionnaire administered, Table 4.1 (b) and Figure 4.1 (c) below was established to numerically illustrate the various categories or classification and their corresponding counts of failures, percentage contribution to the total network outages for the sample space under study, the ratio of occurrence on the two types of networks in operation on the infrastructure as well as variation in the impact per each classification. 
Table 4.1 (b) 2014 - 2016 Summary of Fiber Cut with Reasons

\begin{tabular}{|l|l|c|c|c|c|c|c|}
\hline \multicolumn{7}{|c|}{ 2014-2016 WR\&CR Fiber Cut Classification Statistics } \\
\hline \multirow{2}{*}{$\#$} & \multirow{2}{*}{ Root Causes } & \multirow{2}{*}{ Count of Failures } & \multirow{2}{*}{$\%$} & \multicolumn{2}{|c|}{ Impact } & \multicolumn{2}{c|}{ Network Type } \\
\cline { 5 - 8 } & & & TA & NTA & Backbone & Metro/FTTx \\
\hline 1 & Government Project & 404 & 47.59 & 115 & 290 & 208 & 197 \\
\hline 2 & Private Developers & 396 & 46.64 & 105 & 290 & 235 & 160 \\
\hline 3 & Natural Problems & 3 & 0.35 & 1 & 2 & 2 & 1 \\
\hline 4 & Fire & 6 & 0.71 & 0 & 6 & 4 & 2 \\
\hline 5 & Direct Attack & 3 & 0.35 & 0 & 3 & 3 & 0 \\
\hline 6 & Others & 37 & 4.36 & 12 & 25 & 22 & 15 \\
\hline & Total & 849 & & & & & \\
\hline
\end{tabular}

Sources: Primary data

In the analysis all the fault incidence occurring as a result of fiber cut on both backbone and metro/FTTx network were classified or categorized into six (6) groups. The grouping was done based on the similarity in the fault reasons assigned to the respective fiber cut incident which occurred on the network, with the objective of examining and determining the actual factors responsible for the root causes of the fiber cut menace.

In that regard, it was observed that Government Sponsored Projects and Private Property Developer's activities were the highest contributing groups accounting for the greater percentage of the fiber cut incidence with percentage contribution of $47.59 \%$ and $46.64 \%$ respectively for the two years and eight months period under review. This was followed by "Other Activity" group with $4.36 \%$ whiles the Fire category was responsible for $0.76 \%$ of the total fiber cut incidence in WR\&CR. Tied to this statistical or numerical representation, is a cost component which will be fully exploited in details in subsequent analysis whiles discussing the impact of the fiber cut menace.

The next few paragraphs below provides a details description and characteristics of the respective grouping which subsequently leads in establishing the corresponding root causes accounting for fiber cut attributed to each category.

\section{Government Projects}

According to Morse (2016) Government Project(s) is one of the many channels through which many strategic Governments Projects are delivered. Among the list of government project includes; government transformation and service delivery project, Information and Communication Technology (ICT) and infrastructure project as well as constructional projects.

From the primary data analyzed, it was observed that road and railway construction activities (which involved dig-up or excavation) were responsible for the some significant percentage of the root causes of the fiber cut. Likewise, the government sponsored services delivery projects such as water and electricity expansion and repair projects by Ghana Water Company Limited (GWCL) and Electricity Company of Ghana (ECG) respectively as shown in figure 4.2 below.

\section{Private Property Developers}

Under Private Property Developer category, it was identified that projects owned by individuals and organization either than the government of Ghana also contributed significantly to the fiber cut menace. The activities of these property owners often encroaches on the road reservation where utility services including optical fiber cables are located. The activities of these private land owners also accounted for some significant percentage of the root causes of the fiber cut incidences in the jurisdiction under study. And these projects included;

1. Building of filling stations 2. Building of gas filling station 3. Building of private houses 4. Farming activities

5. Private trenching and digging of pit 6.Construction of drainage 7. Distilling of drainage

\section{Natural Problems}

Natural problems also contributed $0.35 \%$ to total fault count attributed to fiber cut. According to Ezeh et al (2013), natural problems which are responsible for some of the causes of the optical fiber network infrastructure failure are; erosion, floors and force majeure (eg during heavy storm trees which are close to overhead optical cables do fall on them, resulting in fiber breaks or failure. Heavy current from floor waters also do wash away some of the fiber cable). Though the research population differs, the dynamics of this particular category or classification are basically the same irrespective of the jurisdiction selected for respective study, 
hence the evaluation of this paper with respect to "Natural Problem" category reflect the thought or views of Ezeh et al.

Fire

According Crawford (1993), fiber cut or fiber damages due to fire can be defined as cable failures or damage resulting from fire(s) incident to a nearby structure or property and typically affecting overheard or underground optical fiber infrastructure (eg burning of refuse dump or bush fire).

\section{Direct Attacks}

Shake et al (1999) defined direct attack as an act of willful intent to destroy or cause damage to the optical network infrastructure for the purpose of getting a reward be its intrinsic or extrinsic. Generally, small scale mining activities often called "Galamsey", sand winning activities, vandalization and sabotage were cited as the worse cuprite for the category. Crawford (1993) further explained that vandalism or sabotage is a deliberate human activity whose sole purpose is to damages the optical fiber cable. And these activities accounted for $0.35 \%$ of the total network outages accounted for by fiber cuts.

\section{Others}

This category was established for events that also resulted in fiber cut, be it traffic affecting (TA) or non-traffic affecting (NTA). The occurrence of this type of faults or fiber cut(s) are often rare on the network and are normally not aggressive in nature on the optical fiber network infrastructure like the other categories. The likely-hood of its occurrences, impacting on traffic mostly is/are dependent on other cuts occurring elsewhere on the infrastructure of the same topology either concurrently or at a shorter time interval. Broken cores, rodent activities, falling poles and vehicles passing on joint box are among the list cited for this category.

When one or two out of a 48 core or 96 core fiber cable get broken for any reason due to improper splicing previously done, the incidences is describe as "broken core". Normally this happens when fiber cut occur and the team do not join the cables or the cores (ie the strands of fiber) properly it break again with time. The technology applied to the joining of strand(s) of optical fiber cable is what is refer to as splicing.

Normally, the industrial practice for deploying overhead optical fiber cables requires that the cables are implemented on poles. And in certain instances the pole(s) fall down with time for obvious reasons, resulting in optical cable damage.

For rodent activities category, Crawford (1993) describe such fiber failures or fiber cuts as that which is caused by gnawing animals such as mice, rats, gopher and beaver. Moreover, irrespective of the increase in the number of cut counts, there was also significant reduction in the in the number of fiber cut which were traffic affecting as compared to non-traffic affecting fiber cut counts on both the backbone and metro fiber network infrastructure and this generally attributed to facts that there were more single fiber cut than double and triple fiber for the year under comparison. Statistically it was deduced that government sponsored project as well as activities of private developers were the top contributing factors responsible for the frequent fiber cut within the said period. Fiber cuts attributed to government sponsored projects increased in excess of 138 counts over the previous year. Whiles activities of private developers also recorded a similar increases in excess of over 122 fiber cuts over the previous year. The ripple effect of the general spike in the count of fiber cuts between 2014 and 2015 is that, a corresponding high count of both traffic affecting and non-traffic affecting fiber failures were recorded as well as incidences of fiber cut on the backbone and metro fiber infrastructure also increased over the period as shown in figure 4.8 and 4.11.

Table 4.2(a) 2014 Summary of Fiber Cut with Reasons

\section{Fiber Cut With Fault Reason_BB vs MFTTx}

Table 4.2(a) 2014 Summary of Fiber Cut with Reasons
\begin{tabular}{|l|c|c|c|c|}
\hline \multicolumn{2}{|c|}{2014 Fiber Cut With Fault Reason_BB vs MFTTx } \\
\hline $\begin{array}{c}\text { Type Of } \\
\text { Network }\end{array}$ & $\begin{array}{c}\text { Count of } \\
\text { Failure }\end{array}$ & $\boldsymbol{\%}$ & $\begin{array}{c}\text { Traffic } \\
\text { Affecting } \\
(\boldsymbol{\%})\end{array}$ & $\begin{array}{c}\text { Non-Traffic } \\
\text { Affecting } \\
(\boldsymbol{\%})\end{array}$ \\
\hline Backbone & 73 & 68.22 & 16.44 & 83.56 \\
\hline Metro/FTTx & 34 & 31.78 & 50 & 50 \\
\hline Total & 107 & & & \\
\hline
\end{tabular}

Source: Primary Data 
Table 4.2(b) 2014 Summary of Fiber Cut with Reasons

\begin{tabular}{|l|l|c|c|c|c|c|c|}
\hline \multicolumn{7}{|c|}{ 2014 WR\&CR Fiber Cut Classification Statistics } \\
\hline \multirow{2}{*}{$\#$} & \multirow{2}{*}{ Root Causes } & \multirow{2}{*}{ Count of Failures } & \multirow{2}{*}{$\%$} & \multicolumn{2}{|c|}{ Impact } & \multicolumn{2}{c|}{ Network Type } \\
\cline { 5 - 8 } & & & TA & NTA & Backbone & Metro/FTTx \\
\hline 1 & Government Project & 40 & 37.38 & 14 & 27 & 25 & 16 \\
\hline 2 & Private Developers & 65 & 60.75 & 16 & 48 & 46 & 18 \\
\hline 3 & Natural Problems & 0 & 0.00 & 0 & 0 & 0 & 0 \\
\hline 4 & Fire & 0 & 0.00 & 0 & 0 & 0 & 0 \\
\hline 5 & Direct Attack & 0 & 0.00 & 0 & 0 & 0 & 0 \\
\hline 6 & Others & 2 & 1.87 & 1 & 1 & 1 & 1 \\
\hline & Total & 107 & & & & & \\
\hline
\end{tabular}

Source: Primary Data

Figure 4.8 2014 Summary of Fiber Cut with Reasons

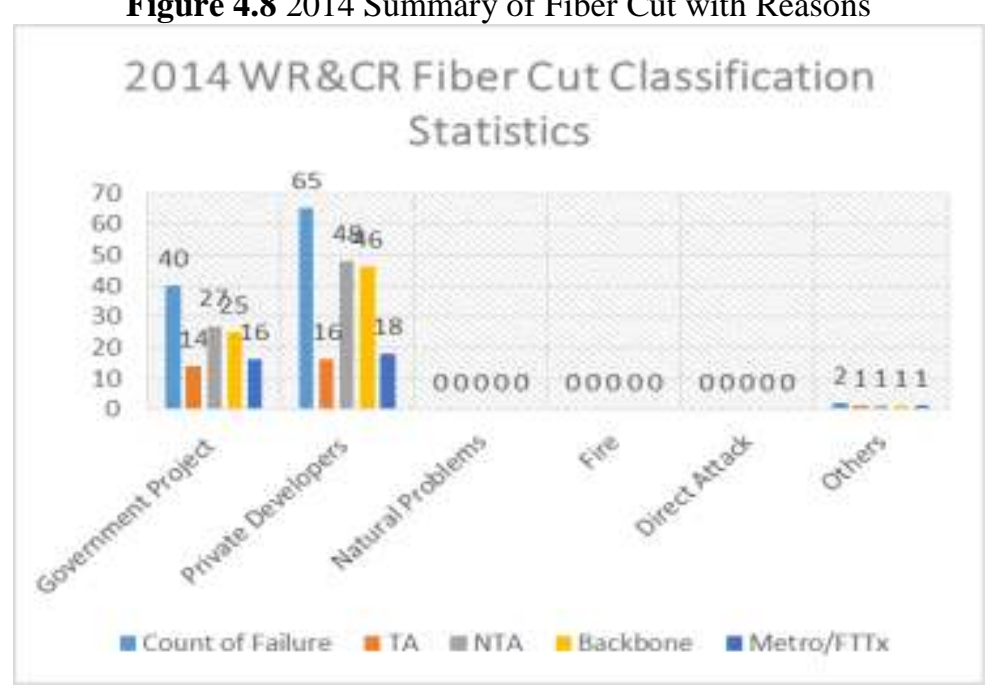

Source: Primary Data

Secondly, even though 2016 has not yet ended (ie data capture from January - August 2016), a comparative analysis with 2015 shows that, by the end of 2016, a similar trend of an incremental growth in the fiber cut counts over the period would occur. This was determined based on the facts that, from figure 4.9 and 4.10 an estimated average of 44 counts of fiber cuts per month from the January - August 2016 had been recorded on both network infrastructure in the jurisdiction under study. Hence by inference, it's most probable that 2016 will close with a total fiber cut counts of 529, should all condition and approach towards project execution remains unchanged. And this would further implied that 2016 total fiber cut counts would be in excess of over 140 over the previous year's total fiber cuts incidences.

Presently 2016 year-to-date (ie August 2016) total estimated fiber cut counts is marginally low as compared with 2015 end-of-year shown in Table 4.3(a) and 4.4(a).

Figure 4.9 2016 CR Fault Count

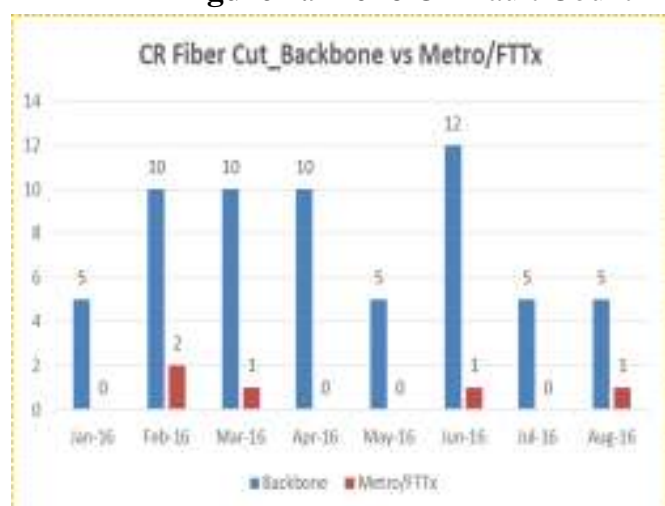

Figure 4.10 2016 WR Fault Count

WR Fiber Cut_Backbone vs Metro/FTTx

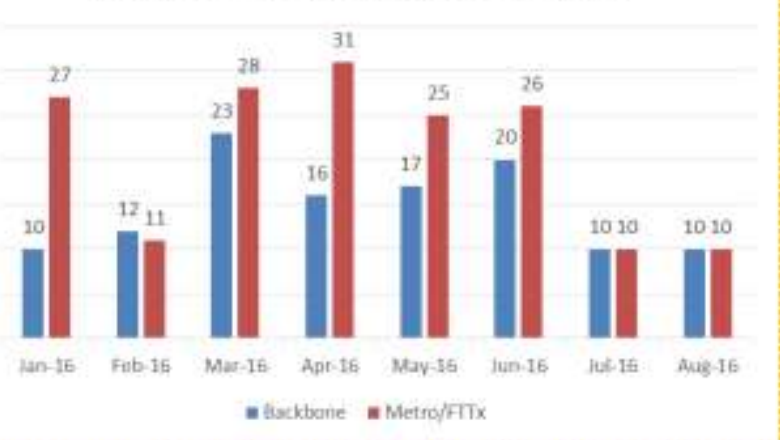

Source: Primary Source Data 
However, irrespective of the rise in the trend, the ratio of the total percentage of traffic affecting (TA) fiber cuts on the backbone declined by $3.44 \%$ against the traffic affecting (TA) fiber cuts incidence recorded on the metro fiber which increased by $8.35 \%$ points for the year 2015 and 2016 under comparison as shown in Table 4.3(a) and 4.4(a).

Table 4.3(a) 2015 summary of Fiber Cut with Reason

\begin{tabular}{|l|c|c|c|c|}
\hline \multicolumn{3}{|c|}{ 2015 Fiber Cut With Fault Reason_BB vs MFTTx } \\
\hline $\begin{array}{r}\text { Type Of } \\
\text { Network }\end{array}$ & $\begin{array}{c}\text { Count of } \\
\text { Failure }\end{array}$ & $\%$ & $\begin{array}{c}\text { Traffic } \\
\text { Affecting } \\
(\%)\end{array}$ & $\begin{array}{c}\text { Non-Traffic } \\
\text { Affecting } \\
(\%)\end{array}$ \\
\cline { 4 - 5 } & & & 12.96 & 87.04 \\
\hline Backbone & 216 & 55.53 & 41.04 & 58.96 \\
\hline Metro/FTTx & 173 & 44.47 & & \\
\hline Total & 389 & & & \\
\hline
\end{tabular}

Source: Primary Source Data

\section{WR\&CR Fiber Cut Classification Statistics}

\begin{tabular}{|l|l|c|c|c|c|c|c|}
\hline \multirow{2}{*}{$\#$} & \multirow{2}{*}{ Root Causes } & \multirow{2}{*}{ Count of Failures } & \multirow{2}{*}{$\%$} & \multicolumn{2}{|c|}{ Impact } & \multicolumn{2}{c|}{ Network Type } \\
\cline { 5 - 8 } & & & & TA & NTA & Backbone & Metro/FTTx \\
\hline 1 & Government Project & 178 & 45.76 & 46 & 133 & 88 & 91 \\
\hline 2 & Private Developers & 187 & 48.07 & 45 & 141 & 110 & 76 \\
\hline 3 & Natural Problems & 1 & 0.26 & 1 & 0 & 1 & 0 \\
\hline 4 & Fire & 1 & 0.26 & 0 & 1 & 0 & 1 \\
\hline 5 & Direct Attack & 2 & 0.51 & 0 & 2 & 2 & 0 \\
\hline 6 & Others & 20 & 5.14 & 10 & 10 & 10 & 10 \\
\hline & Total & 389 & & & & & \\
\hline
\end{tabular}

Source: Primary Source Data

Figure 4.11 2015 Summary of Fiber Cut with Reasons

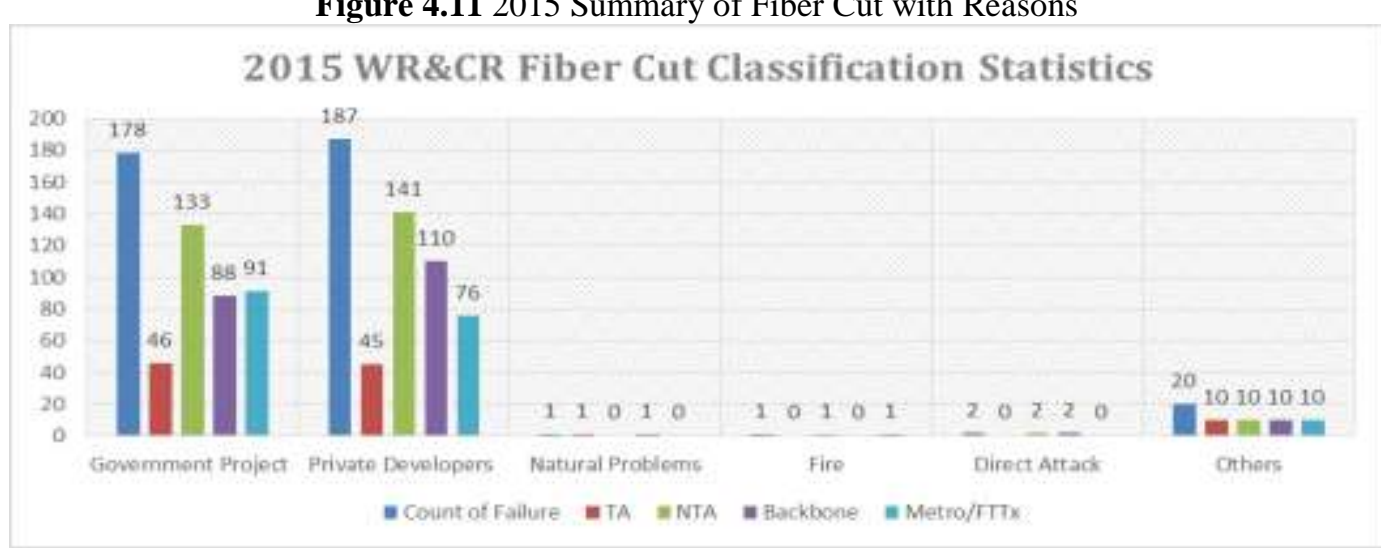

Again, from the 2015 and 2016 year-on-year analysis, it was established that activities of government project as well as private developers accounted for over 178 and 187 counts of fiber cut failures in 2015 and also 186 and 144 for 2016 respectively with majority of the fiber cuts incidence being non-traffic affecting (NTA) fiber cuts on the backbone network infrastructure as shown in Table 4.3(b) and 4.4(b). 
Table 4.4(a) 2016 Summary of Fiber Cut with Reasons

\begin{tabular}{|l|c|c|c|c|}
\hline \multicolumn{3}{|c|}{2016 Fiber Cut With Fault Reason_BB vs MFTTx } \\
\hline \multirow{2}{*}{$\begin{array}{c}\text { Type Of } \\
\text { Network }\end{array}$} & $\begin{array}{c}\text { Count of } \\
\text { Failure }\end{array}$ & $\%$ & $\begin{array}{c}\text { Traffic } \\
\text { Affecting } \\
(\boldsymbol{\%})\end{array}$ & $\begin{array}{c}\text { Non-Traffic } \\
\text { Affecting } \\
(\boldsymbol{\%})\end{array}$ \\
\hline Backbone & 189 & 53.54 & 9.52 & 90.48 \\
\hline Metro/FTTx & 164 & 46.46 & 49.39 & 50.61 \\
\hline Total & 353 & & & \\
\hline
\end{tabular}

Table 4.4(b) 2016 Summary of Fiber Cut with Reasons

\begin{tabular}{|c|l|c|c|c|c|c|c|}
\hline \multicolumn{7}{|c|}{2016 WR\&CR Fiber Cut Classification Statistics } \\
\hline \multirow{2}{*}{$\#$} & \multirow{2}{*}{ Root Causes } & \multirow{2}{*}{ Count of Failures } & \multirow{2}{*}{$\%$} & \multicolumn{2}{|c|}{ Impact } & \multicolumn{2}{c|}{ Network Type } \\
\cline { 5 - 8 } & & & TA & NTA & Backbone & Metro/FTTx \\
\hline 1 & Government Project & 186 & 52.69 & 54 & 133 & 97 & 90 \\
\hline 2 & Private Developers & 144 & 40.79 & 43 & 100 & 77 & 66 \\
\hline 3 & Natural Problems & 2 & 0.57 & 0 & 2 & 1 & 1 \\
\hline 4 & Fire & 5 & 1.42 & 0 & 5 & 4 & 1 \\
\hline 5 & Direct Attack & 1 & 0.28 & 0 & 1 & 1 & 0 \\
\hline 6 & Others & 15 & 4.25 & 5 & 10 & 8 & 7 \\
\hline & Total & 353 & & & & & \\
\hline
\end{tabular}

Source: Primary Source Data

Figure 4.12 2016 Summary of Fiber Cut with Reasons

Figure 4.13 Pareto Chart Analysis On Fiber Cuts

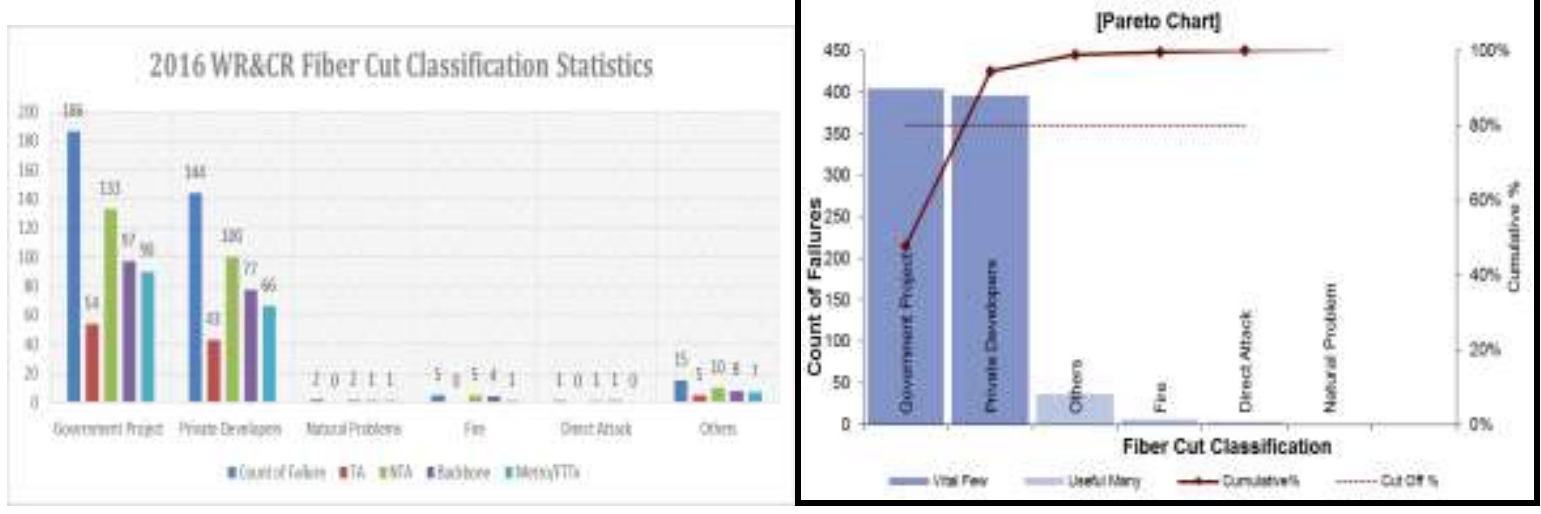

Source: Primary Source Data

Therefore in concluding this section in line with it objectives of determining the category(s) of activities and their corresponding root causes and factors accounting for the greater percentage of the fiber cut incidence in the jurisdiction under study; first, a Pareto analytical tool was applied to the entire primary data to establish figure 4.13 shown below. And it was deduced from the application of the model that government sponsored project as well as activities of private developers were the top contributing groups or categories responsible for the frequent fiber cut in the last two years and eight month in western and central region.

Hence in principle, the top $20 \%$ category that needs to be drilled further to identify it roots causes and its related factors in order to arrive at recommendation that will address $80 \%$ of the fiber cut menace were activities involving Government Sponsored Project and Private Developers. Consequently, the results obtained is also a direct reflection of the results obtained from the year-on-year comparative analysis discussed previously.

Secondly, the Ishakawa analytical tool or Causes-and-Effect diagram was identified as the most suitable models to apply to the results obtained from figure 4.13 above in order to arrive at the definite root causes and their related factors accounting for the various respective activities responsible for the fiber cut phenomenon focusing on the categories which falls within the $20 \%$ obtained from the Pareto model. That is; 
1. Government Sponsored Project 2. Private property developers

In the final analysis, the various categories and their corresponding root causes were critically examined and evaluated to establish the under listed as the key contributing factors accounting for the fiber cut menace in the jurisdiction under study; (ie for both government sponsored project and private developers been the highest contributor to the menace);

\section{Negligence of Excavation Operators}

According to the Fiber Infrastructure Planning Manager, MTN deploys its optical fiber infrastructure in accordance with all the obligatory requirement which includes provision of sub-surface marks on its ROW to alert encroacher.

As discussed previously in chapter two, industrial best practices for deploying underground optical fiber network requires that;

- The cable is deployed strictly in accordance with right-of-way (ROW) obtained from the permitting and regulatory agencies. And deviation from the approved ROW will required a pre-approval.

- The right-of-way obtained along the highway corridors is often not less than 30 meters from the center or the median of the road which must be approved by GHA. For ROW in the metropolis, DUR approves on the

- Location upon final sites inspection of the proposed route is submitted to it outlet, due to the nature of the structure configuration in the urban community.

- The depth of the trench for laying the optical fiber cable should not be less than 1.5 meters (as shown in figure 4.16).

- A caution tap must be deployed $30 \mathrm{~cm}$ above the fiber cable, whether or not it's a direct burying technique applied or cable is buried in a sub-ducts, before final backfilling is done.

- Sub-surface markers or marker poles must be deployed on the fiber route at specified interval to enhance the optical fiber rout visibility. In spite of all these provision, some excavator operators blatantly ignore all the signage and causes damage to the underground optical network infrastructure.

\section{Ignorance about the Presence of the Underground Optical Fiber Infrastructure}

It was identified in the analysis carried out that, some users or encroachers of the road reservation are totally ignorance about the presence of the underground optical fiber infrastructure within the utility corridor. Such that even when they meet the optical fiber cable during excavation they ignore its and causes damage to it. Though the survey conducted could not establish whether or not the perpetrators of fiber cuts (beside government sponsored project) do have permit or ROW to engage the road reservation. It is however certain that activities of fuel and gas filling station developer's as well as private property developers and others are the worst culprits. Considering the trend and the frequency of occurring, the paper is inclined to believe that most of these perpetrators don't have the requisite permit to engage the utility corridor as they do, whiles working on their sites. Secondly, the paper has less doubt that perpetrators of fiber cut has full knowledge of the presence of the optical fiber cable within the road reservation just as they do for water and electricity.

According to the Senior Manager for Network Field Operations most of these recorded incidences are reported to the permitting and regulatory agencies for redress but most often either little or no action is taken against the perpetrators.

\section{Lack of Coordination between the Permitting and Regulating Agencies}

According to the Senior Manager for Network Field Operation, lack of effective coordination between the permitting and regulatory agencies such as Ghana Highway Authority (GHA), Department of Urban Roads (DUR), Regional Coordinating Council (RCC) and Metropolitan, Municipal and District Assembly (MMDA) in respect of permit issuance and project coordination along the rural and urban roads also contributes to fiber cut challenges been experienced by the telecom industry in Ghana. These bodies mandated by law to issues permit or ROW and regulate the activities of the contractors, organization, institution etc who engage the road reservation, often conduct their operations in silos which generate conflicting data on the field of execution.

$\mathrm{He}$ is of the opinion that the current system and process adopted by these individual bodies needs to be streamlined in order to improve on the processes for procuring ROW and also eliminated the chance of duplication of ROW or conflicting data.

\section{Ineffective Monitoring and Control of the Road Reservations}

Research has proven that modern technologies such as Ground Penetration Radar (GPR) are used to locate, truck, control and monitor underground utility services in the road reservation to minimize or eliminated the chances of causing damage to existing underground infrastructure such as the optical fiber cable network during project execution. According to Goyal, et al (2014), in the last decade GPR has proved its ability to act 
as a powerful geophysical tool for subsurface investigations. In a related article by Nissen et al, it was cited that the technology has been accepted by many developed countries such the United States (US) and Europe as the most efficient and cost effective way of locating and identifying underground cables. Quite unfortunately, in Ghana such technology is not incorporated in the ROW acquisition process to ensure that existing underground infrastructures within the road reservation are protected during project execution. Consequently, the traditional ROW acquisition processes also contribute the root the causes of the fiber cut menace.

\section{Lack of Adequate and Visible Sub-Surface Indicators or Markers}

Sub-surface infrastructures indictors or markers, which sometime are referred to as marker poles, are often deployed on the fiber route (in accordance with best practice) to enhance visibility of the location of the sub-surface infrastructure within the road reservations (including optical fiber cable) for easy of identification and also to protect them from been damaged. However, in the study conducted, it was revealed that though the company (MTN) deploys market poles (as show in figure 4.15 below) on it optical fiber route, they are often been damaged or stolen by unidentified persons. For that reason even when prior notification are provided for impending project involving excavation work it become difficult to locate the cable position and eventually lead to damaging the cable in the process.

\section{Variation in the obtained ROW and As-built drawings}

Other factors that significantly accounts for the fiber cut menace is/are the variation in the acquired ROW and the implemented ROW (otherwise called the as -built). In some cases, due to on the ground challenges uncounted during execution, deviation from originally acquired ROW are implemented in order to deploy the cable on the "line of less resistance" with the intent to update the original acquired ROW with relevant permitting agencies. But unfortunately, these variation are not well documented in order to inform future acquisition, hence resulting duplication or conflicting of ROW.

\section{Conclusion}

On the bases of the primary source data reviewed relative to the jurisdiction under study and further subjecting it thorough analysis and interpretation, it was conclusive that activities of government sponsored projects and private developers were largely responsible for the fiber cut menace experienced in Western and Central Region. It was also established that direct attack (in the form of vandalism and sabotage), fire incidences and natural disaster among others were also responsible for quite significant percentage of the fiber cut incidences which in effect impacts on the organization revenue generation ability negatively, increases its operational expenditure exponentially as well as dwindling its commercial fortunes in strategic market places within the strategic business unit.

\section{Recommendation}

On the bases of the finding and results obtained it is recommended that key actors of the industry actively collaborate with stakeholder to collectively work together to drive awareness and sensitization on the importance of this national asset and it implication when there are damages.

In that regards, the detailed recommendation has been consolidated into two major categories to be discussed, namely; the short to medium recommendation and medium to long term recommendation.

\section{4) Short to Medium Term Recommendation Education Campaign}

The NCA as a regulator of the industry, with full understanding of the implication of the fiber cut incidences, must champion an educational campaign aimed at the following under listed organizations who either have a stake in the management of the utility corridors

or is/are equally users of the road reservation or an encroacher on the facility.

1. Association of Road Contractors

2. Association of Fuel and Gas Station Operators

3. Ghana Highway Authority

4. Department of Urban Road

5. Association of Small Scale Miners

6. The Regional Police Command

7. The Regional Coordinating Council

The objective of the campaign is to solicit the support of these key stakeholders in assisting to protect the existing or already deployed fiber infrastructure. This can be done through either a formal or informal engagement such as community forum, workshops, courtesy calls etc. 


\section{Formal or Informal Training}

It is also important that the human resource (such as excavator operators and laborers) which are used to engage the utility corridor or the road reservation on various projects are equipped with requisite knowledge on how to work effectively along or within the road reservation without damaging any existing infrastructures. From the analysis done, often, damage caused to sub-surface infrastructure including fiber cables has been as a result of the actions or inactions of these resources engaged for the execution of various projects.

\section{Enforcement of the Law}

The Electronic Communications Act 2008, Section 77 in the constitution of the Republic of Ghana states "A person who recklessly, maliciously or negligently damages, removes or destroys a facility, used in connection with the operation or provision of electronic communications network or service, commits an offence, and is liable on summary conviction to a fine of not more than three thousand penalty units or to a term of imprisonment of not more than five years or both".

From the analysis carried out, it was identified that some of the perpetrators of the act of cutting the fiber cable does so with the full knowledge of the presence of the cables. Some even blatantly ignores sub-surface inscription with clear descriptions and indications of the owners of the infrastructure and goes ahead to damage the fiber cable(s). In such circumstances, the support of the law enforcement agencies and the judiciary will be required to investigate and sanction the appropriate punishment to the culprit(s) to serve as deterrent to others.

\section{Enhanced Maintenance Culture of the Road Reservation}

As part of the short to medium term measures to curb the fiber cut menace in the jurisdiction under study, it is recommended that the maintenance culture of all individual stakeholders including Telecom companies who own right-of-ways in the road reservation or utility corridor are consolidated and executed by the permitting and regulatory bodies mandated by law. Thereby enhancing the visibility of the entire road reservation by weeding along the facility regularly and clearly indicating the boundaries of the reservation along some strategic routes in Ghana at a reasonable fee in addition to the fee charged for the permit. Additionally, the telcos will then also need to enhance the visibility of their right-of-way by deploying more maker poles along the fiber route within the road reservation. And by this approach, encroachers would be left with no option than to call the respective infrastructure owners before they commence any digging.

\section{Medium to Long Term}

Beyond the short to medium term recommendations targeted at minimizing the frequency of the fiber cut incidences, a long term strategic approach is required to further reduce the frequency of the cut to the bearers minimum if not totally eliminated. It is in that regard that the following long term recommendation are made to guide future deployment;

\section{The Use of Real Time Information Management System or Technology.}

A real time information management system or technology is a computer based system that interfaces with other applications and functions to generate a rapid responds to communications by immediately updating the respective master files and/or generating a response in a time frame fast enough to keep an operation moving at its required speed. According to Himanshu et al n.d, the adaptation of real time information systems with an organizations existing operational models, enhance visibility and create inter-organizational processes that links and facilitate the delivery of seamless information across the various functions of an organization. It also enable organizations make adequate demand planning using advance tools and techniques to predict future demand. Hence, state agencies mandated by law to regulate the issuance and utilization of the road reservation such as the Ghana Highway Authority and Department of Urban Road, must leverage on the advent of this technology to streamline their operations process as well as consolidate and synchronize their data base in relation to rightof-way acquisition to enhance its operational efficiency.

\section{Develop an Enhanced Flow Chart Process for Acquiring Right-of-Way}

The need to review, develop and implement an enhanced flow chart process to guide and inform the processes leading to the acquisition of right-of-way within the road reservation, to make it compelling enough for organizations and persons who acquire or wishes to acquire right-of-way to provide credible postimplementation feedback with clear indication of whether or not any variations were implemented during execution. By so doing the agency(s) can develop a credible data base or records to inform future acquisition. Secondly, the enhanced flow chart process should be able to trigger a notification in the form of an email or sms to all the users of the utility corridor on an impending project be it road, railway, fuel or gas station developer which may encroach on their right-of-way. In that sense, owners of the infrastructure could take the necessary proactive measure to protect their optical cable in the scope of the project be it private or government. 
Moreover, the process should also compel the contractor whom the said contract has been awarded to, to provide feedback to the custodians of the project in the form of certificate of engagement endorsed by all the user of the utility corridor including the telecom companies before mobilization funds are issues.

\section{Build of Mandatory Right-of-Way for Optical Fiber Infrastructure}

As it was established earlier, the majority of the network outages attributed to fiber cut incidences are as a results of government sponsored project, which in effect compromising on the network quality of service for which the regulator (ie NCA) acting on behalf of the government of Ghana penalize operators who fail to pass the monthly mandatory key performance indicators (KPI) target month-on-month. It is therefore appropriate for the government of Ghana to acquire and develop some sections of the road corridor across the country as mandatory right-of-way in accordance to industrial standards for the deployment of optical fiber cable across the country. This can be effectively be incorporated or integrated into the government's annual road network expansion and development programs. And subsequently lease them to optical fiber network infrastructure developer at a fee. As suggested by Gyaase and Takyi, (2014) that government investment in these passive infrastructure and make them more efficient because governments have access to majority of the rights-of-way, and lease them to the communication companies. Williams (2010) also share the same thought that investing into restructuring and redesigning and making the rights-of-way readily available to network developers at low cost should be the way forward in addressing most of the issues accountable for the frequent fiber cut.

\section{Enhancing the fiber cable coating}

Usually, manufacture of optical fiber cable protect the fiber strand or the core with a plastic coasting made of polymers which are brittle and breaks beyond its elastic limit when slitters force is applied on it. It's therefor important to explore the use of kurvler as a substitute for fiber cable outer protection coating. Kurvler is known to be ductile and can withstand high tensile stress. With this property as the fiber cable coasting, it will be difficult to break or cut. Hence, such can be used for aerial solution to combat against vandalism and sabotage. In the light of the above recommendations, this paper carries the strongest conviction that once the recommendations are implemented moving forward, the incidences of fiber cut will reduce drastically in the interest of all.

[1]. Dhliwayo. J, (2012), "Ready to re-build backhaul?", Southern African Wireless Communications, [online] available on http://www.corning.com/media/world wide/coc/documents/Fiber/Resource\% $20 \quad$ Center\%20-\%20LongHaul/SAWC_ RebuildBackhual_July Aug 2012 .pdf, Accessed on $12^{\text {th }}$ July 2016.

[2]. Banigbe, O., (2014), "Tigo deploys overhead fibre in Ghana", Biztechafrica.com, [online] available on http://www. biztechafrica.com/article/tigo-deploys-overhead-fibre-ghana /9218/\# .V4bMRPmLTIU, Accessed on $13^{\text {th }}$ July 2016.

[3]. AdAms, L., (2009), "OVERriew of Fibre Infrastructure Opportunities in the UbuntuNet Region", InTERnational

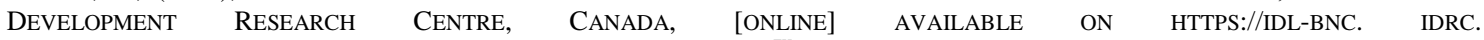
CA/DSPACE/BITSTREAM/10625/40489/1/128889.PDF, ACCESSED ON $6^{\text {TH }}$ AUGUST 2016.

[4]. Afzal, I. M., n.d., Effect of Fiber Cut in Pakistan, Telenor Pakistan (Pvt) Ltd, http:// www.sanog.org/resources/sanog6/idrees-pkfibercut.pdf, Accessed on $13^{\text {th }}$ July 2016

[5]. Allwood, M. C., (2011), "The distinction between qualitative and quantitative research methods is problematic", [online] available on http://users.polisci.wisc.edu/ schatz berg /ps816/Allwood 2012.pdf, Accessed on $21^{\text {st }}$ August 2016

[6]. Held, G., (1999), "Understanding Data Communications", $6^{\text {th }}$ Edition, Published by New Riders Publishing, [online] available on http://technet.microsoft.com/en-us/library/ bb7 26936.aspx, Accessed on $24^{\text {th }}$ June 2016.

[7]. Domfeh, A. K., (2012), "MTN Ghana decries impact of fibre cuts on operations", [online] available on http://business.myjoyonline.com/pages/news/201204/84133.php, Accessed on 24 $4^{\text {th }}$ June 2016.

[8]. Ezeh, G. N. and Ibe, G. O., (2013), "Efficiency of Optical Fiber Communication for Dissemination of Information within the Power System Network, Journal of Computer Engineering, Vol. 12, Issue 3, PP 68-75, [online] available on http:// www.iosrjournals .org/iosr-jce/papers/Vol12-issue3/K01236875 .pdf ?id =2066, Accessed on $4^{\text {th }}$ August 2016.

[9]. Ezeh, N. G., et al., (2013), "Severity Index Analysis of The Problems of Optical Fiber Communication in Nigeria: A Case Study Of South Eastern Nigeria", Federal University of Technology, Owerri Nigeria, Vol. 4 No. 1, [online] available on http://www.savap.org.pk /journals/ARInt./Vol.4(1)/2013(4.1-46).pdf, Accessed on $28^{\text {th }}$ July 2016.

[10]. Massa, N., (2008), "Fiber Optic Telecommunication", Springfield Technical Community College Springfield, Massachusetts, [online] available on https://spie.org/ Documents/Publications/00\%20STEP \%20Module\%2008.pdf, Accessed on $23^{\text {rd }}$ July 2016

[11]. Marcuse, D., (2012), "Principe of Optical Fiber Measurement", Academic Press, New York, [online] available on https://books.google.com.gh/books?hl=en\&lr= \&id=aOkke ZTOQW gC\&o i=fnd\&pg=PP1\&dq=explain+optical+fiber+ damage\&ots $=5 \mathrm{D} 7 \mathrm{k}$ i58G ue\&sig=fSf8RMR6ayb1WUXQg FzbRJ11Gv4\&redir_ esc $=\mathrm{y} \# \mathrm{v}=$ onepage\&q\&f$=\mathrm{false}$, Accessed on $9^{\text {th }}$ August 2016.

[12]. Crawford, D., (1993), "Fiber Optics Cable Dig-Up: Causes and Cure”, MCI Telecommunication Corporation, [online] Available on https://transition .fcc.gov/nric/nric-1/abody.pdf, Accessed on $15^{\text {th }}$ July 2016.

[13]. Johnson, M., (2009), "Optical fibres, cables and systems", ITU Telecommunication Standardization Sector, [online] available on https://www.itu.int/dms_pub/itu-t/opb/hdb/T-HDB-OUT.10-2009-1-PDF-E.pdf, Accessed on 17 July 2016.

[14]. Anon, (2002), "Installation Guide For Optical Fibre Cable", [online] available on http://www.nexans.fr/ France/group/doc/fr_FR/INSTALLATION_GUIDE_Rev.1.0.pdf, Accessed on 17 ${ }^{\text {th }}$ July 2017. 
[15]. Anon, (2004), “Ghana Telecommunication Policy”, Republic Of Ghana, Ministry of Communication, [online] available on http://www.nca.org.gh/downloads/ Ghana_Telecom_Policy_2005.pdf, Accessed on 14 $4^{\text {th }}$ August 2016.

[16]. Anon, (2014), "Broadband Applications \& Construction Manual”, CommScope, [online] available on file:///D:/Downloads/CO107147.2-EN-Fiber\%20Optics\%20 Construction\% 20M anual.pdf, Accessed on $29^{\text {th }}$ July 2016.

[17]. Anon, (2014), "Fault Cases and Countermeasures for Optical Fiber Cables in Optical Network Facilities", Practical Field Information about Telecommunication Technologies, Vol. 12 No. 6, [online] available on https://www.ntt-review.jp/ archive/ntttechnical.php? contents=ntr20140 6pf1.pdf\&mode=show_pdf, Accessed on 23 $3^{\text {rd }}$ July 2016.

[18]. Anon, (2014), "Quality Of Service Performance Report, February-June 2014”, Uganda Communication Commission, [online] available on http://ucc.co.ug/f iles/ downloads/Quality\% 20of\%20Service\%20report \%20for\%20February-June\%202014.pdf, Accessed on $30^{\text {th }}$ July 2016

[19]. Anon, n.d., "NCA Data Form 105 (Domestic Fiber Optic Cable Providers)", [online] available on http:// www.nca.org.gh/downloads/Data_Collection_Form_Domestic_Fibre_Optic_Cable_Providers.pdf, Accessed on $6^{\text {th }}$ August 2016.

[20]. Anon, n.d., "Research methodology", [online] available on http://uir.unisa.ac.za/bitstream /handle/10500/1450/04chapter3.pdf, Accessed on 17th August 2016

[21]. Gyaase, O. P. and Takyi, A., (2014), “A Case For Public Financing Of Broadband Internet Infrastructure In Ghana”, International Journal Of Scientific \& Technology Research, Vol. 3, Issue 2, [online] available on http://www.ijstr.org/final-print/ feb2014/ACase-For-Public-Financing-Of-Broadband-Internet-Infrastructure-In-Ghana.pdf, Accessed on 14 ${ }^{\text {th }}$ August 2016.

[22]. Williams, J. D. M., (2010), "Broadband For Africa: Developing Backbone Communications Networks", The International Bank for Reconstruction and Development, [online] available on https://openknowledge. worldbank.org/ bitstream /handle/10986/2422/536430PUB0Broa1 01\%20Official0U se0Only 1.pdf?sequence=1, Accessed on $14^{\text {th }}$ August 2016.

[23]. Grover, D. W., (2003), "Failure Impacts, Survivability Principles, and Measures of Survivability", [online] available on http://www.ece.ualberta.ca/ g rover/book/ Grover_Sample_Chapt_3-Failures_and_Survivability.pdf, Accessed on $15^{\text {th }}$ July 2016.

[24]. Grover, D. W., (2004), "Fiber Cable Failure Impacts, Survivability Principles, and Measures of Survivability", [online] available on http://www.informit.com /articles/ article.aspx?p=169456, Accessed on $31^{\text {st }}$ July 2016.

[25]. Matt Hoffman, (2002), “Cable Cut", [online] available on http://all.net/CID/Attack/papers Cable Cuts. html, Accessed on 15 $5^{\text {th }}$ July 2016.

[26]. Shake, H. T., (1999), "Assessing Network Infrastructure Vulnerabilities to Physical Layer Attacks", Massachusetts Institute of Technology, [online] available on http://csrc. nist.gov /nissc/ 1999/proceeding /papers/p18.pdf, Accessed on $1^{\text {st }}$ August 2016.

[27]. T. H. Shake, B. Hazzard, D. Marquis, Assessing Network Infrastructure Vulnerabilities to Physical Layer Attacks, Lincoln Laboratory, Massachusetts Institute of Technology Lexington, Massachusetts, http://csrc.nist.gov/nissc/1999 /proceeding /papers/p18.pdf,

[28]. Doshi, A. J. et al, (2012), "Root Cause Analysis Using Ishikawa Diagram For Reducing Radiator Rejection”, International Journal of Engineering Research and Applications, Vol. 2, Issue 6, pp.684-689, [online] available on http://www.ijera. com/papers/Vol2_ issue6/ CY26684689.pdf, Accessed on $20^{\text {th }}$ August 2016

[29]. Patel et al J. P., (2014), "Application of Quality Control Tools in Taper Shank Drills Manufacturing Industry: A Case Study", International Journal of Engineering Research and Applications, Vol. 4, Issue 2, pp.129-134, [online] available on http://www.ijera.com /papers/Vol4_issue2/Version\%201/S4201129134.pdf, Accessed on 20 ${ }^{\text {th }}$ August 2016.

[30]. Bhosale, D. S. et al., (2013), "Quality improvement in manufacturing processes using SQC tools", International Journal of Engineering Research and Applications, Vol. 3, Issue 3, pp.832-837, [online] available on http://www.ijera.com/papers/ Vol3_issue3/EM338 32837.pdf, Accessed on 20 $0^{\text {th }}$ August 2016.

[31]. Goyal, H. et al (2014), "Ground Penetrating Radar", International Journal of Advanced Research in Science, Engineering and Technology, Vol. 1, Issue 3, [online] available on http://www.ijarset .com/upload/2014/october/6_Ground.pdf, Accessed on 26 ${ }^{\text {th }}$ September 2016. 